\title{
Water supply risk on the Colorado River: Can management mitigate?
}

\author{
Balaji Rajagopalan, ${ }^{1,2}$ Kenneth Nowak, ${ }^{1}$ James Prairie, ${ }^{3}$ Martin Hoerling, ${ }^{4}$ \\ Benjamin Harding, ${ }^{5}$ Joseph Barsugli, ${ }^{2,4}$ Andrea Ray, ${ }^{4}$ and Bradley Udall ${ }^{2,4}$ \\ Received 14 December 2008; revised 3 June 2009; accepted 1 July 2009; published 21 August 2009.
}

[1] Population growth and a changing climate will tax the future reliability of the Colorado River water supply. Using a heuristic model, we assess the annual risk to the Colorado River water supply for 2008-2057. Projected demand growth superimposed upon historical climate variability results in only a small probability of annual reservoir depletion through 2057. In contrast, a scenario of $20 \%$ reduction in the annual Colorado River flow due to climate change by 2057 results in a near tenfold increase in the probability of annual reservoir depletion by 2057 . However, our analysis suggests that flexibility in current management practices could mitigate some of the increased risk due to climate changeinduced reductions in flows.

Citation: Rajagopalan, B., K. Nowak, J. Prairie, M. Hoerling, B. Harding, J. Barsugli, A. Ray, and B. Udall (2009), Water supply risk on the Colorado River: Can management mitigate?, Water Resour. Res., 45, W08201, doi:10.1029/2008WR007652.

[2] Reliability of water supply from the reservoirs on the Colorado River (Figure 1; see Appendix A for details on the data used) has been the backstop supporting population growth and economic expansion in the southwest United States. It is the tremendous reservoir storage capacity, currently about 60 million acre feet $\left(1 \mathrm{MAF}=1.233 \times 10^{9} \mathrm{~m}^{3}\right)$ or roughly four times the annual average flow in the river, that has historically rendered the water supply reliable even when taxed by severe drought such as during the early 1990s. Fifty MAF of this storage is located in two reservoirs: Lake Mead and Lake Powell. The annual basin deliveries have risen in recent decades and now approach the annual average river flow (Figure 1, top insert). With the projection for further demand increase [U.S. Department of the Interior, 2007], the reliability of the water supply becomes increasingly dependent on reservoir storage.

[3] The critical importance of storage was highlighted during the recent drought. While the region is no stranger to dry periods, the severe prolonged drought that began in 2000 , coupled with demands associated with increasing population and economic growth over several decades, has lowered the reservoirs to historic low levels [Fulp, 2005]. In response to the ongoing drought, the Secretary of the Interior, in consultation with the Basin states and other stakeholders, developed an interim plan for managing Lake Powell and Lake Mead, particularly for drought and low reservoir conditions, through 2026. Known as the "Interim Guidelines"

\footnotetext{
${ }^{1}$ Department of Civil, Environmental, and Architectural Engineering, University of Colorado at Boulder, Boulder, Colorado, USA.

${ }^{2}$ Cooperative Institute for Research in Environmental Sciences, University of Colorado at Boulder, Boulder, Colorado, USA.

${ }^{3}$ Bureau of Reclamation, University of Colorado at Boulder, Boulder, Colorado, USA.

${ }^{4}$ NOAA Earth System Research Laboratory, Boulder, Colorado, USA.

${ }^{5}$ Earth and Environmental Division, AMEC, Inc., Boulder, Colorado, USA.

Copyright 2009 by the American Geophysical Union. 0043-1397/09/2008WR007652\$09.00
}

[U.S. Department of the Interior, 2007], these guidelines provide the opportunity to gain valuable operating experience using several innovations in Colorado River management, including the coordinated operation of Lakes Powell and Mead for the full range of reservoir operations, a shortage strategy for the Lower Basin, and a mechanism to foster water conservation and water transfers in the Lower Basin.

[4] The region's water managers are increasingly assessing the resilience of Colorado River storage and the capabilities to meet the complex and often competing management objectives that constitute the Law of the River (see Appendix A) [Fulp, 2005; Nathanson, 1978]. Of emerging concern is how climate change may alter those capabilities. Water managers and their stakeholders are now considering how the reliability of the water supply would be threatened if recent depleted hydrometeorology is a new norm [Fulp, 2005]. This study seeks to further quantify the risk of water storage failure in future years using existing management assumptions for demand growth, known historical climate variability, and the projected reductions in Colorado River flow due to climate change.

[5] The preponderance of evidence from extensive recent literature on the probable effect of climate change is that the Colorado River average annual flow will decline [Bates et al., 2008; Christensen and Lettenmaier, 2007; Christensen et al., 2004; McCabe and Wolock, 2008; Milly et al., 2005; Nash and Gleick, 1991; Revelle and Waggoner, 1983; Seager et al., 2007], although an earlier assessment included one simulation with a substantial increase in future annual flows under climate change [National Assessment Synthesis Team, 2000]. The magnitude of reduction is uncertain given the complexity of physical processes and terrain effects that determine Colorado River flow and given the range of climate model projections of temperature and precipitation. Furthermore, the nonlinearities in the interactions between the various physical processes have a significant impact on the simulation of extremes and, consequently, on management policies [Georgakakos et al., 2005; Georgakakos and Graham, 2008; 


\section{Colorado River Basin}

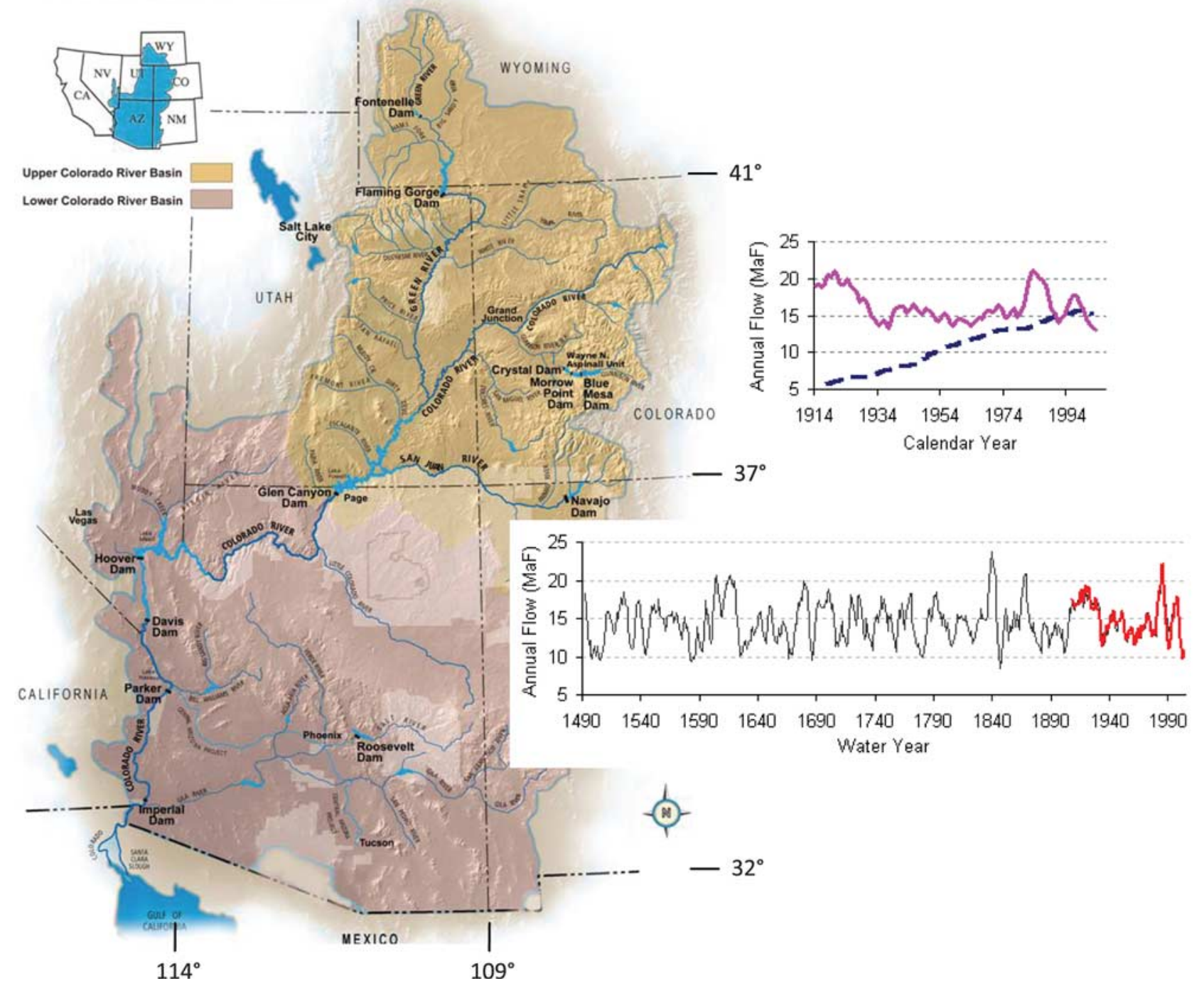

Figure 1. Colorado River Basin including major dams. The top inset shows water demand and losses and supply in the Colorado River Basin. Shown are a 9-year moving average of the natural flow above Imperial Dam, Arizona (solid red line), and a 9-year moving average of the total consumptive use in the Lower and Upper basins, including reservoir evaporation from Flaming Gorge, Blue Mesa, Morrow Point, Lake Powell, Lake Mead, Lake Mohave, and Lake Havasu; bypass flow to Cienega de Santa Clara; and losses due to native vegetation between Davis and Imperial dams (dashed blue line). Mexico deliveries are in accordance with a 1944 treaty with Mexico. The bottom inset shows the 5-year moving average of paleoreconstructed flows at Lees Ferry, Arizona [Woodhouse et al., 2006]. The red overlay is the natural flow from the observational period.

Yao and Georgakakos, 2001]. A majority of results derived from the recent Coupled Model Intercomparison Project (CMIP3) multimodel database of climate change simulations indicate a reduction of average annual streamflow within a range of -6 to $-20 \%$ by midcentury [Ray et al., 2008]. As improved projections of climate change impacts on Colorado River flow emerge, a sharper view of the basin's risk profile will be warranted that would include meaningful probabilistic assessments of outcomes based on more precise knowledge of the uncertainty in climate change. Recognizing these caveats, we used a simple and reasonable assumption that the climate change-induced drying will be superimposed on year-to-year Colorado River flow variations as seen in the historical and paleoreconstructed record [Meko et al., 2007; Woodhouse et al., 2006] (Figure 1, bottom insert).

[6] Given these climate and demand stresses, Colorado River water supply risk is likely to increase in the future; can management mitigate the enhanced risks? This paper follows several in the recent literature [Barnett and Pierce, 2008; Jain and Eischeid, 2008; McCabe and Wolock, 2007] but adds to their analyses. We consider the entire system storage, include tributary inflows between Lakes Powell and Mead and inflows and losses below Mead, and dynamically compute reservoir evaporation. Furthermore, we consider a suite of management alternatives to investigate potential flexibility in the system to mitigate risk because storage in the system is 
Table 1. Descriptions of Alternatives Considered in This Study ${ }^{\mathrm{a}}$

\begin{tabular}{|c|c|c|c|}
\hline Alternative & Demand & Shortage Policy & $\begin{array}{l}\text { Initial Storage } \\
\text { (MAF) }\end{array}$ \\
\hline A & $\begin{array}{l}\text { 7.5 MAF to LB, 1.5 MAF to MX and UB deliveries } \\
\text { per EIS depletion schedule }\end{array}$ & $\begin{array}{l}333 \mathrm{KAF} \text { DS when } \mathrm{S}<36 \%, 417 \mathrm{KAF} \text { DS when } \mathrm{S}<30 \% \\
\text { and } 500 \mathrm{KAF} \text { DS when } \mathrm{S}<23 \%\end{array}$ & 30 \\
\hline B & $\begin{array}{l}\text { 7.5 MAF to LB, 1.5 MAF to MX and UB deliveries } \\
\text { per EIS depletion schedule }\end{array}$ & $\begin{array}{l}5 \% \text { DS when } \mathrm{S}<36 \%, 6 \% \text { DS when } \mathrm{S}<30 \% \\
\text { and } 7 \% \text { DS when } \mathrm{S}<23 \%\end{array}$ & 30 \\
\hline $\mathrm{C}$ & $\begin{array}{l}\text { 7.5 MAF to LB, } 1.5 \text { MAF to MX and UB deliveries } \\
\text { at a } 50 \% \text { rate of increase as compared } \\
\text { to the EIS depletion schedule }\end{array}$ & $\begin{array}{l}5 \% \text { DS when } \mathrm{S}<36 \%, 6 \% \text { DS when } \mathrm{S}<30 \% \\
\text { and } 7 \% \text { DS when } \mathrm{S}<23 \%\end{array}$ & 30 \\
\hline $\mathrm{D}$ & $\begin{array}{l}7.5 \mathrm{MAF} \text { to LB, } 1.5 \mathrm{MAF} \text { to MX and UB deliveries } \\
\text { at a } 50 \% \text { rate of increase as compared } \\
\text { to the EIS depletion schedule }\end{array}$ & $\begin{array}{l}5 \% \text { DS when } \mathrm{S}<36 \%, 6 \% \text { DS when } \mathrm{S}<30 \% \\
\text { and } 7 \% \text { d DS when } \mathrm{S}<23 \%\end{array}$ & $60^{\mathrm{b}}$ \\
\hline E & $\begin{array}{l}7.5 \mathrm{MAF} \text { to } \mathrm{LB}, 1.5 \mathrm{MAF} \text { to } \mathrm{MX} \text { and UB deliveries } \\
\text { at a } 50 \% \text { rate of increase as compared } \\
\text { to the EIS depletion schedule }\end{array}$ & $\begin{array}{l}5 \% \text { DS when } \mathrm{S}<50 \%, 6 \% \text { DS when } \mathrm{S}<40 \%, 7 \% \text { d DS } \\
\text { when } \mathrm{S}<30 \% \text { and } 8 \% \text { DS when } \mathrm{S}<20 \%\end{array}$ & 30 \\
\hline
\end{tabular}

${ }^{\mathrm{a}}$ LB, Lower Basin; MX, Mexico; UB, Upper Basin; DS, delivery shortage; S, storage. Per EIS depletion schedule the total deliveries are projected to be 13.9 MAF by 2026 and 14.4 MAF by 2057 .

${ }^{\mathrm{b}}$ One alternative with full initial storage (D) illustrates the effects of a full system.

determined by management alternatives as well as the physical system.

[7] We estimate the risk to the water supply in each year for the 50-year period 2008-2057 under a suite of demand growth, management alternatives, and climate change assumptions. Risks are estimated using a water balance model that realistically represents the inflows and outflows of the Colorado River system water supply (see the model description in Appendix A). Natural streamflow variability is simulated using a stochastic streamflow generation technique that combines the paleoreconstructed and historic observed flows [Prairie et al., 2008] (see also Appendix A for a brief description of the generation technique) to generate streamflow sequences for use in probabilistic risk analysis. We consider two scenarios of climate change that are within the range of current projections: a linear reduction in annual average flow of 10 and $20 \%$ over the 50 -year period, henceforth referred to as $\mathrm{CC} 10$ and $\mathrm{CC} 20$, respectively. We considered five alternatives (Table 1), each consisting of two components: (1) a demand component and (2) shortage criteria in operating the reservoir. The alternatives highlight the sensitivity of risk to various combinations of demand or shortage policy. The demand component includes reductions that range from $2.5 \%$ (alternative A) to $8 \%$ (alternative E) of demand of the projected demand by 2057, and the reservoir levels at which deliveries are first curtailed range from $36 \%$ (alternative A) to $50 \%$ (alternative E) of full reservoir capacity. These alternatives provide a starting point for policy makers to assess the potential reductions in risk associated with a range of different alternatives. However, the way to achieve these "management alternatives" is beyond the scope of this work and depends on interpretation of the Law of the River and on the agreements can be reached with stakeholders across the basin.

[8] Figure 2a shows the probability of depleting active system reservoir storage, henceforth termed drying, in each year for the 50-year period as computed for various management alternatives and assumes no climate change-induced average flow reduction. The risk is below 4\% in 2026 for all management and demand options. With current management (a)

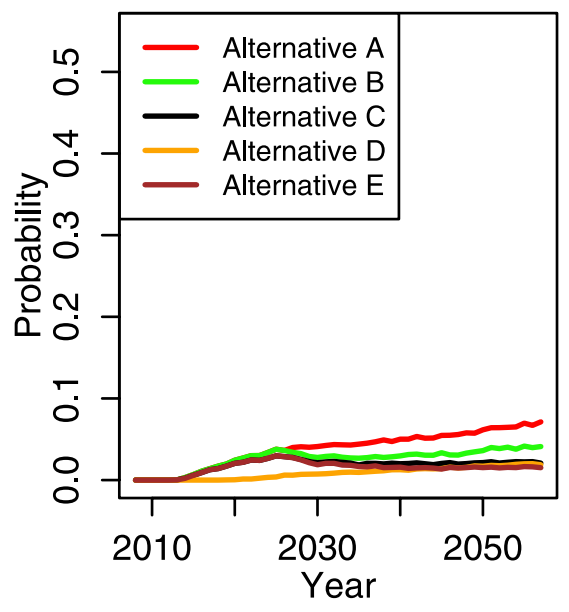

(b)

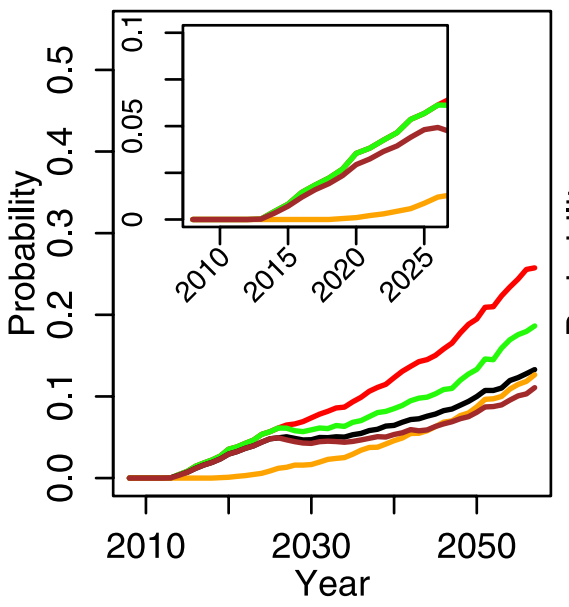

(c)

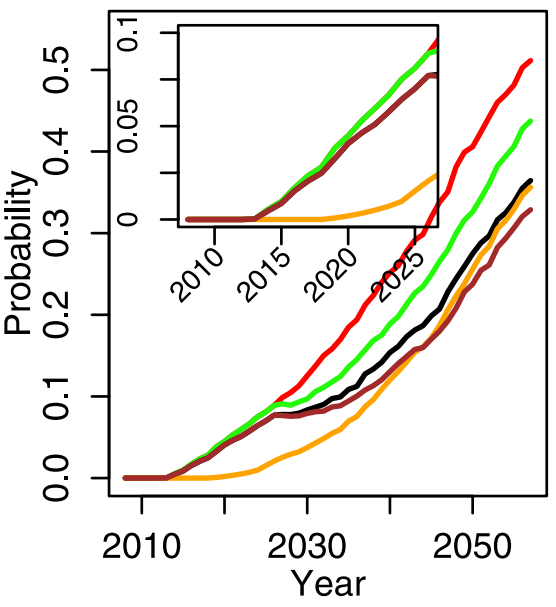

Figure 2. (a) Risk of drying (depleting active system-wide reservoir storage in a given year) for five management alternatives under assumptions of no climate change-induced average flow reduction with an initial demand of 13.5 MAF. (b) Same as Figure 2a but for natural climate variability and a superimposed $10 \%$ reduction in the annual average inflow over the 50 -year period. Inset shows the risk in the near term for the period 2008-2026. (c) Same as Figure $2 \mathrm{~b}$ but for $20 \%$ reduction in annual average inflow. 
(a)

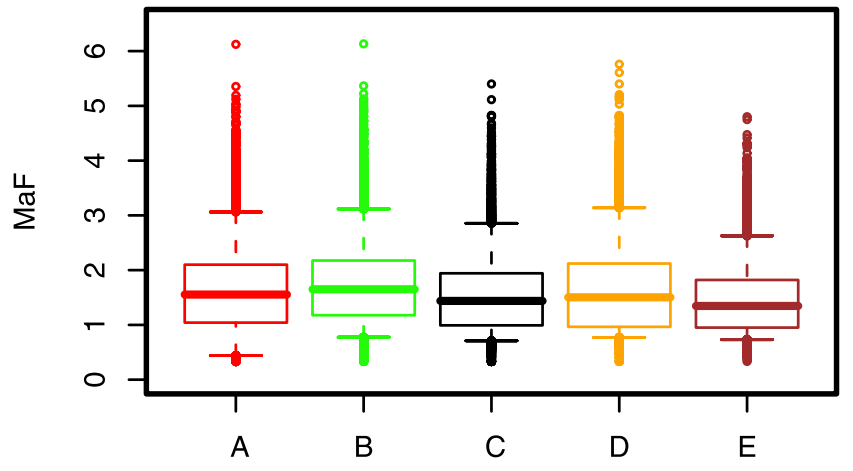

(b)

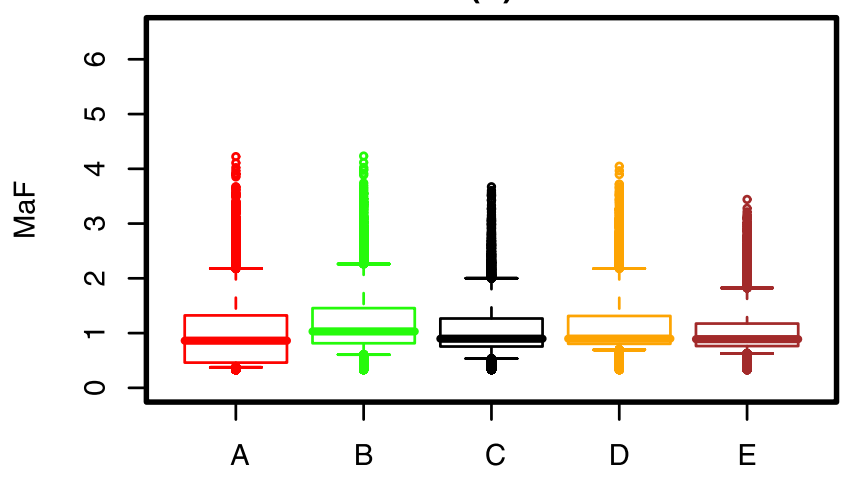

Figure 3. (a) Box plot of average deficit volume over deficit events in a 50-year period from natural climate variability and a superimposed $20 \%$ reduction in the annual average inflow over the 50-year period. (b) Same as Figure 3 a but for $10 \%$ reduction in annual average inflow.

practices for shortages in the United States under the recent Interim Guidelines (alternative A) assumed to continue for the entire 50-year period, the risk probability increases to about $7.5 \%$ toward the end of the 50 -year period because of increasing demand. Alternatives that include reduced rate of demand growth (alternative C) and adaptive management (alternative E) are effective in mitigating this risk to as low as $1.5 \%$. We note that the near-term risk is sensitive to initial reservoir storage volume (Figure 2; compare alternative D on the basis of assumed full initial system storage of $60 \mathrm{MAF}$ with all other curves based on $50 \%$ initial storage), with little threat of drying until after 2026.

[9] The risk of drying in the $\mathrm{CC} 10$ climate change scenario for the management alternatives is shown in Figure $2 \mathrm{~b}$. Through 2026 the risk is around $6.25 \%$ or less (see Figure $2 \mathrm{~b}$ inset), which is similar to that from no climate change seen above. However, the risk increases significantly in the following 30 -year period as annual inflow is progressively depleted because of climate change at a time when demand is increasing. For the current U.S. shortages and demand growth alternative (alternative A) the risk increases to about $26 \%$. Our analysis indicates that a moderate shortage strategy and demand growth management can greatly mitigate this risk. An aggressive shortage and demand management (alternative E) could reduce the risk further to about $11 \%$, similar to levels that exist under natural climate variability.

[10] The drying risk profiles under the CC20 scenario are displayed in Figure 2c. The risk under all management alternatives remain less than $9 \%$ out to 2026 (see Figure 2c inset), comparable to the risk from natural climate variability and the $\mathrm{CC} 10$ scenario. This underscores the near-term resiliency of the system even under a depleting inflow regime due to climate change and an increasing demand profile. However, the risk escalates within the subsequent 30-year period. For the current management alternative (alternative A) the risk increases to about $51 \%$ (almost a fourfold increase in a 30 -year period) compared to $26 \%$ in the $\mathrm{CC} 10$ scenario (Figure $2 b$ ). Moderate shortage strategy and demand growth management alternatives (alternatives $\mathrm{B}-\mathrm{D}$ ) reduce the risk to only between 36 and $43 \%$; even the aggressive shortage and demand growth management alternative (alternative E) reduces the risk only to around $33 \%$, both equally high, suggesting that even more aggressive strategies may be required in order to bring water supply reliability within acceptable standards.

[11] The distribution of volume of average annual deficits (i.e., the amount of water that could not be delivered on average in each deficit event) under $\mathrm{CC} 20$ and $\mathrm{CC} 10$ are shown in Figure 3. We define deficit to include both shortages prescribed by policy as well as additional delivery failures due to reservoir drying. For this metric of water system function, under CC20 (Figure 3a) all the management alternatives show similar median shortage per deficit event, all in the range of 1.35-1.65 MAF. However, the range and standard deviation for the aggressive management alternative (alternative E) is smaller (25\%) relative to alternative A. Under $\mathrm{CC10}$, the deficit magnitudes also exhibit similar median values, but the standard deviation is reduced by as much as 33\% (Figure 3b). This may be a preferable attribute to secure for a water system because stakeholders may favor reduced shortage variability (even though they may be more frequent) than larger shortages, which, though less frequent, can be devastating. These risk profiles should be viewed as an overall system risk that may be useful for basin wide planning and management, whereas impacts on individual stakeholders will vary on the basis of the allocation practices that result from the Law of the River and the water rights administered by the individual states.

[12] During the recent dry period, water consumption has decreased in the Upper Basin in response to the decrease in streamflow, primarily because of physical shortages at diversion points, shortages induced from water rights competition, and other responses of the system to drought. The estimated consumption for the Upper and Lower basins in 2006 is 12.7 MAF [U.S. Department of the Interior, 2008], which is less than the value of 13.5 MAF assumed in the above analysis (and in other studies, including those of Barnett and Pierce [2008] and U.S. Department of the Interior [2007]). In order to investigate the effect on risk of this response, we repeated the analysis using an initial demand of 12.7 MAF while applying the same yearly increments in demand growth per EIS schedule as in the earlier scenarios (Figure 4). In this the total demand is projected to be 13.1 MAF by 2026 and 13.6 MAF by 2057 . We found the near-term risk to be less than 3\% (see Figure 4 inset) and to be about 34\% at 2057 under the current management alternative, which is about a $33 \%$ reduction in the risk from a starting demand of 13.5 MAF (Figure 2c). Other alternatives also show a similarly large reduction in risk. It is noteworthy that a $6 \%$ reduction in demand translates to a 33\% reduction in drying 


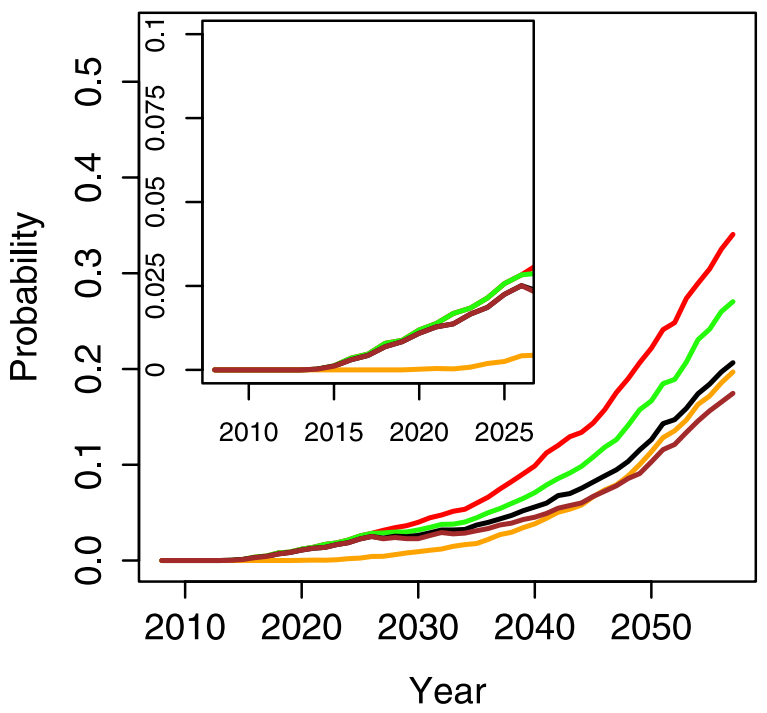

Figure 4. Same as Figure $2 \mathrm{c}$ but with an initial demand of 12.7 MAF.

risk. Under the CC10 scenario the drying risk was found to be less than $2.5 \%$ at 2026 and less than $10 \%$ by 2057 (figure not shown), similar to the risks from no climate change-induced average flow reduction (Figure 2a). Actual future risks will most likely fall between the risks shown for these two demand curves as future demands will likely vary between these curves because of the influence on future demand from flow variability.

[13] The confluence of three factors, increasing delivery obligations anticipated because of population growth, the likelihood of multiyear droughts, and potential flow reductions due to climate change, poses an increasing threat to the water supply of the Colorado River system, especially after the mid 2020s. Our assessment indicates that the risk of drying in the near term (pre-2026) is less than $9 \%$ under any climate scenario and management alternative, demonstrating the resilience of the system. However, post 2026, under the CC10 scenario the risk of drying increases to about $26 \%$, and under the CC20 scenario risk escalates nonlinearly to about 51\% under current management practices. Our assessment also indicates that a variety of management alternatives can greatly mitigate these increased risks, though they would require implementation well in advance of significant detection of local climate change in order to preserve reservoir storage. In particular, under $\mathrm{CC} 10$, an aggressive shortage strategy and demand growth management strategy reduces the risk to about $11 \%$.

[14] The threat from climate change and demand growth to the water supply is real and consistent with prior studies [Barnett and Pierce, 2008; Jain and Eischeid, 2008; McCabe and Wolock, 2007]. Whereas one study claims reservoir drying is imminent [Barnett and Pierce, 2008] and that we are already in "crisis," we find that risks in 2026 are relatively low. Under CC20 the rate of risk increase per year post 2026 is greater than double that of the interim period. It is our conclusion that flexibility within the existing framework of agreements exists to mitigate a significant fraction of the longterm risk. We argue that the relatively small risk of drying in the next 2 decades should not lull policy makers into inaction because if by 2026 the detection of changing climate confirms incipient $20 \%$ reduction in annual average flow due to a climate change signal, then the policy options available may be limited in their ability to mitigate the large risk.

[15] Our simple model assessment is not meant to guide policy nor to invoke specific stakeholder action, given our idealized treatments of water resources, but to inform the discussion of risks and the development of more detailed modeling exercises. There is sufficient realism, however, that the results should warrant ongoing discussion on the need to reduce uncertainties in climate change projections by scientists and the need to explore increased flexibility in water resource management by decision makers.

\section{Appendix A}

\section{A1. Data Sets Used}

[16] Data sets used in this study are as follows. (1) Natural streamflow data at the key location of Lees Ferry, Arizona, through which more than $90 \%$ of the entire river flow passes, are maintained and documented by the Bureau of Reclamation [U.S. Department of the Interior, 2005]. Naturalized streamflows are computed by removing anthropogenic impacts (i.e., reservoir regulation, consumptive water use, etc.) from the recorded flows. For this study the annual water year (September-October) natural streamflow for the period 1906-2005 was used. (2) The annual water year streamflow, reconstructed from tree ring information at Lees Ferry, Arizona [Woodhouse et al., 2006], for the period 14901997, labeled Lees-B, is available at http:/www.ncdc.noaa. gov/paleo/pubs/woodhouse2006. (3) Data regarding projected demands, reservoir storage, and reservoir surface area-evaporation relationships (Figure A1) are found in the Interim Guidelines documentation [U.S. Department of the Interior, 2007].

\section{A2. Law of the River}

[17] The treaties, compacts, decrees, statutes, regulations, contracts and other legal documents and agreements applicable to the allocation, appropriation, development, exportation, and management of the waters of the Colorado River Basin are often referred to as the Law of the River [U.S. Department of the Interior, 2007; Nathanson, 1978]. A1though there is no single, universally agreed upon definition of the Law of the River, it is useful as a shorthand reference to describe this longstanding and complex body of legal agreements governing the Colorado River.

\section{A3. Stochastic Streamflow Simulation}

[18] Ten thousand fifty-year streamflow ensemble sequences, capturing natural climate variability, are generated by combining the paleoreconstructed and observed flow data [Prairie et al., 2008]. This method first generates the hydrologic "state" (wet or dry) on the basis of a nonhomogeneous Markov chain model fitted to the paleoreconstructed data, then the flow magnitude is generated by resampling a natural flow from the observed period, conditioned on the generated hydrologic state and the previous year's flow [Lall and Sharma, 1996]. This method generated ensembles with a mean flow of $15 \mathrm{MAF}$, which are consistent with the 1906-2005 observed natural flows. The incoming flow between lakes Powell and Mead and flow below Mead from this resampled historical year is taken as 


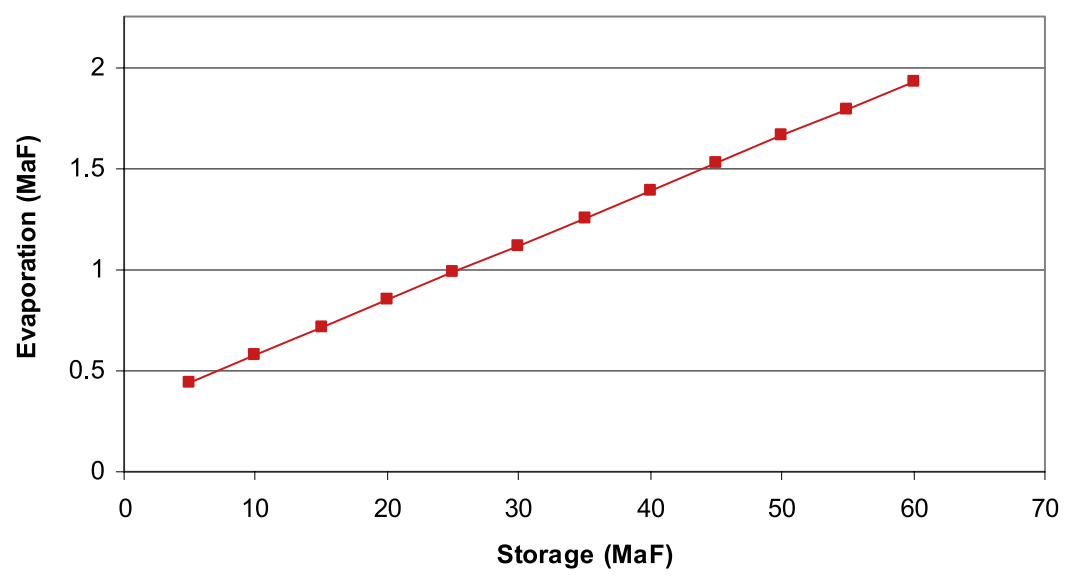

Figure A1. Storage-evaporation relationship in the basin. Surface area is approximated from an empirical storage-surface area function determined from data in Appendix A of the Interim Guidelines [U.S. Department of the Interior, 2007]. Evaporation is computed by multiplying surface area with the average of the annual evaporation coefficients provided for Powell and Mead, also found in Appendix A.

the simulation of the intervening flow. Climate change projections are incorporated by imposing a percentage reduction to the stochastically generated flows. The climate change reductions start of at $0 \%$ in 2008 and linearly decrease to either $-10 \%$ (1.5 MAF on average) or $-20 \%$ (3 MAF on average) over the 50-year period.

\section{A4. Water Balance Model}

[19] A simplified but realistic water balance model of the Colorado River water supply based on [Barnett and Pierce, 2008] of the form change in storage $=$ inflow - outflow is used in a heuristic manner to explore potential futures on the river and implications of different management strategies. The inflow is the sum of flow at the Lees Ferry, Arizona, gauge and the intervening flow. The active storage capacity in the major water supply units is $60 \mathrm{MAF}$, and it is represented as a single storage unit. Outflow includes the deliveries to the Upper (4.5 MAF) and Lower basins and Mexico (9 MAF), transmission losses in the Lower Basin $(11.5 \%$ of Lower Basin outflow), and reservoir evaporation computed from the surface area-evaporation relationship (Figure A1). Transmission losses account for evaporation at lakes Mohave and Havasu, native vegetation consumptive use, and operational losses consisting of bypass flows to the Cienega de Santa Clara and overdeliveries to Mexico. Bank storage was not incorporated because available data indicate it does not provide a net gain or loss to the system over multiple simulations. The initial reservoir storage is set to be $30 \mathrm{MAF}$, a conservative estimate of the available live storage as of September 2008. As per current schedules, the Lower Basin demand is stabilized, and the Upper Basin demand is projected to grow at a specified rate [U.S. Department of the Interior, 2007]. For additional detail on net system water balance and a systematic comparison of the work of Barnett and Pierce [2008] see J. J. Barsugli et al. (Comment on "When Will Lake Mead Go Dry?," submitted to Water Resources Research, 2009).

[20] Acknowledgments. Funding support from NOAA through the Western Water Assessment program is gratefully acknowledged. The first author is thankful to NCAR for providing a visitor fellowship during the course of this study. Support from BOR to the third author and resource support from CADSWES are thankfully acknowledged. Thanks are due to
Russ Callejo and Carly Jerla for their valuable inputs. The authors would like to thank Kosta Georgakakos, Allen Hamlet, and an anonymous reviewer and Dennis Lettenmaier for their helpful and insightful comments that improved the manuscript. Note that reference by Barnett and Pierce [2009] was published while this paper was in the final stages of review. In that paper the authors present a reduced risk of drying compared to their earlier work, and their new risk estimates are similar to those presented here.

\section{References}

Barnett, T. P., and D. W. Pierce (2008), When will Lake Mead go dry?, Water Resour. Res., 44, W03201, doi:10.1029/2007WR006704.

Barnett, T. P., and D. W. Pierce (2009), Sustainable water deliveries from the Colorado River in a changing climate, Proc. Natl. Acad. Sci. U. S. A., 106, 7334-7338, doi:10.1073/pnas.0812762106.

Bates, B. C., et al. (Eds.) (2008), Climate change and water, technical paper, 210 pp., Intergov. Panel on Clim. Change Secr., Geneva, Switzerland.

Christensen, N. S., and D. P. Lettenmaier (2007), A multimodel ensemble approach to assessment of climate change impacts on the hydrology and water resources of the Colorado River Basin, Hydrol. Earth Syst. Sci., 11, $1417-1434$

Christensen, N. S., et al. (2004), The effects of climate change on the hydrology and water resources of the Colorado River basin, Clim. Change, 62, 337-363, doi:10.1023/B:CLIM.0000013684.13621.1f.

Fulp, T. (2005), How low can it go?, Southwest Hydrol., 4, 16-17, 28.

Georgakakos, K. P., and N. E. Graham (2008), Potential benefits of seasonal inflow prediction uncertainty for reservoir release decisions, J. Appl. Meteorol. Climatol., 47, 1297-1321, doi:10.1175/2007JAMC1671.1.

Georgakakos, K. P., et al. (2005), Utility of ten-day climate model ensemble simulations for water resources applications in Korean watersheds, Water Resour. Manage., 19, 849-872, doi:10.1007/s11269-005-5605-x.

Jain, S., and J. K. Eischeid (2008), What a difference a century makes: Understanding the changing hydrologic regime and storage requirements in the Upper Colorado River basin, Geophys. Res. Lett., 35, L16401, doi:10.1029/2008GL034715.

Lall, U., and A. Sharma (1996), A nearest neighbor bootstrap for resampling hydrologic time series, Water Resour. Res., 32, 679-693, doi:10.1029/95WR02966.

McCabe, G. J., and D. M. Wolock (2007), Warming may create substantial water supply shortages in the Colorado River basin, Geophys. Res. Lett., 34, L22708, doi:10.1029/2007GL031764.

McCabe, G. J., and D. M. Wolock (2008), Joint variability of global runoff and global sea surface temperatures, J. Hydrometeorol., 9, 816-824, doi:10.1175/2008JHM943.1.

Meko, D. M., C. A. Woodhouse, C. A. Baisan, T. Knight, J. J. Lukas, M. K. Hughes, and M. W. Salzer (2007), Medieval drought in the upper Colorado River Basin, Geophys. Res. Lett., 34, L10705, doi:10.1029/ 2007 GL029988.

Milly, P. C. D., et al. (2005), Global pattern of trends in streamflow and water availability in a changing climate, Nature, 438, 347-350, doi:10.1038/nature04312. 
Nash, L. L., and P. H. Gleick (1991), Sensitivity of streamflow in the Colorado Basin to climatic changes, J. Hydrol., 125, 221-241, doi:10.1016/0022-1694(91)90030-L.

Nathanson, M. N. (1978), Updating the Hoover Dam documents, Bur. of Reclam., U.S. Dep. of the Inter., Denver, Colo.

National Assessment Synthesis Team (2000), Climate Change Impacts on the United States: The Potential Consequences of Climate Variability and Change Overview Report, 154 pp., Cambridge Univ. Press, Cambridge, U. K.

Prairie, J., K. Nowak, B. Rajagopalan, U. Lall, and T. Fulp (2008), A stochastic nonparametric approach for streamflow generation combining observational and paleoreconstructed data, Water Resour. Res., 44, W06423, doi:10.1029/2007WR006684.

Ray, A. J., et al. (2008), Climate Change in Colorado; A Synthesis to Support Water Resources Management and Adaptation, Western Water Assess., Boulder, Colo.

Revelle, R. R., and P. E. Waggoner (1983), Effects of a carbon dioxideinduced climatic change on water supplies in the western United States, in Changing Climate, pp. 419-432, Natl. Acad., Washington, D. C.

Seager, R., et al. (2007), Model projections of an imminent transition to a more arid climate in southwestern North America, Science, 316, $1181-$ 1184, doi:10.1126/science. 1139601.

U.S. Department of the Interior (2005), Natural flow and salt computation methods, Bur. of Reclam., Salt Lake City, Utah.

U.S. Department of the Interior (2007), Final environmental impact statement Colorado River interim guidelines for lower basin shortages and coordinated operations for lakes Powell and Mead, Bur. of Reclam., Boulder City, Nev.

U.S. Department of the Interior (2008), Upper Colorado River Basin consumptive uses and losses report: 2006-2010 (provisional), Bur. of Reclam., Salt Lake City, Utah.

Woodhouse, C. A., S. T. Gray, and D. M. Meko (2006), Updated streamflow reconstructions for the Upper Colorado River Basin, Water Resour. Res., 42, W05415, doi:10.1029/2005WR004455.

Yao, H., and A. Georgakakos (2001), Assessment of Folsom Lake response to historical and potential future climate scenarios 2. Reservoir management, J. Hydrol., 249, 176-196, doi:10.1016/S0022-1694(01)00418-8.

J. Barsugli and B. Udall, Cooperative Institute for Research in Environmental Sciences, University of Colorado at Boulder, Boulder, CO 80309, USA.

B. Harding, Earth and Environmental Division, AMEC, Inc., Boulder, CO 80302, USA.

M. Hoerling and A. Ray, NOAA Earth System Research Laboratory, Boulder, CO 80305, USA.

K. Nowak and B. Rajagopalan, Department of Civil, Environmental, and Architectural Engineering, University of Colorado at Boulder, Boulder, CO 80309, USA. (balajir@colorado.edu)

J. Prairie, Bureau of Reclamation, University of Colorado at Boulder, Boulder, CO 80309, USA. 